\title{
How Socioeconomic Status Effects Instruction in Middle School Classrooms
}

\author{
Dr. Kristen Jones, EdD \\ Walden University \\ $100 \mathrm{~S}$ Washington Ave \#900 \\ Minneapolis, MN 55401, USA \\ Dr. Michelle McCraney, EdD \\ Senior Contributing Faculty \\ Walden University \\ $100 \mathrm{~S}$ Washington Ave \#900 \\ Minneapolis, MN 55401, USA \\ Dr. Sunddip Panesar Aguilar \\ University of St. Augustine \\ 1 University Blvd, St. Augustine, Florida \\ United States
}

\begin{abstract}
In suburban school district, the gap in mathematics performance between students considered economically disadvantaged and economically no disadvantaged was slowly widening as evidenced by state test scores. The purpose and research questions of this instrumental case study were designed to: (a) identify what Grades 6, 7 and 8 mathematics teachers perceive the role socioeconomic status plays in ability to learn mathematics and to (b) understand what teachers believe affects their perceptions of students' ability to learn mathematics. Participants were middle school mathematics teachers from a small, diverse, suburban school district. Data was gathered through semistructured interviews; and publicly available aggregated demographic data. Identified themes were used to understand how teacher perceptions affect mathematics instruction and student success. The results indicated that a position paper outlining a course of action intended to increase teachers' understanding of the needs of students from low socioeconomic backgrounds, be created and presented to the district leadership.
\end{abstract}

Keywords: mathematics teachers, socioeconomic status, mathematics instruction, poverty, universal design for learning, parental involvement, student motivation, teacher preparation.

\section{Introduction}

Researchers have asserted that nationally, teachers should meet the needs of all students, without bias, as best teaching practice (Basque \&Bouchamma, 2016; Byerley et al., 2017; Sieben \& Johnson, 2018). The inclusion of professional development for teachers specifically in mathematics in a district's strategic improvement plan, acknowledges that the local district believes there is a problem in the teaching of mathematics. According to the policy handbook; from a small, diverse, suburban school district, teacher evaluation rubrics and communication with the assistant superintendent, teachers were required to meet the needs of all students in the district, regardless of socioeconomic status (SES). According to the Department of Elementary and Secondary Education, at the local level, in the past 5 years the number of economically disadvantaged students testing in the warning/failing category in mathematics has increased in percentage (i.e., 33\% in Grade 6, 12\% in Grade 7, and 11\% in Grade 8), while the number of noneconomically disadvantaged students testing in the warning/failing category has decreased in percentage (i.e., $42 \%$ in Grade 6,3\% in Grade 7, and 5\% in Grade 8). Teachers' perceptions of SES may influence their classroom teaching and expectations for their students (Tienken, 2012). A study on teacher constructs regarding homeless students and families found that teacher perceptions impacted relationships with students and families experiencing financial hardships (Powers-Costello \& Swick, 2011). Powers-Costello and Swick (2011) also recommended that more research is needed regarding professional development for educators who serve homeless children. Reviewing the research regarding influences on student achievement, Rollin (2013) stated that, "Despite efforts to try to be sympathetic toward the plight of students who come from poverty, there are times when we are influenced by societal assumptions and stereotypes associated with poverty" (p. 50). 
This statement suggests that despite teachers' desires to meet the needs of all students, their own assumptions and perceptions may affect how students from different socioeconomic backgrounds are taught.

\subsection{Problem}

While there is current research examining the issue of SES on student achievement (Tienken, 2012) and on how teachers' perceptions affect student achievement (Tomul, Celik, \& Tas, 2012), there is less research focused on understanding how teachers' perceptions about the effect of SES on learning readiness affects teaching strategies and student success. Often times, teachers do not know what the expectations should be for low-income students, or how to adjust their teaching for these students to succeed (Jensen, 2013). Currently, there is significant research showing that both teacher perceptions and SES each affect student achievement separately. There is less research showing the effects of teacher perceptions of SES and the relationship of how these perceptions relate to student achievement. To address this problem locally, data was gathered that defined what teacher perceptions of SES and student achievement in mathematics were, as well as data that explained what factors teachers believe affected their perceptions of student ability to learn mathematics.

\subsection{Purpose and Guiding Research Questions}

The purpose of this qualitative, instrumental case study approach was to explore and gain insight to the perceptions and biases mathematics teachers may have, related to the ability of low SES students in mathematics classrooms. The research questions were formulated specifically for middle school mathematics' teachers from a small, diverse, suburban school district, based on documented state test performance data, that identified a widening gap in test scores between disadvantaged and non-disadvantaged students. The qualitative research questions of this research study were as follows:

RQ 1: What are Grades 6, 7 and 8 mathematics teachers' perceptions about how their students' socioeconomic status affects the ability to learn mathematics?

RQ 2: What do Grades 6, 7 and 8 mathematics teachers believe influences their own perceptions of students' ability to learn mathematics?

\subsection{Conceptual Framework}

According to Collins (2009), social reproduction theory pursues the idea that schools are a catalyst in perpetuating social inequalities and not places of equal opportunity. Auwarter and Aruguete (2008) argued that if teachers have preconceived beliefs that SES and gender predetermine student success, then teachers will not work as actively to reach these students. Auwarter and Aruguete (2008) determined teacher perceptions of hypothetical students by altering the scenarios of SES and gender. Participants in their study were given a questionnaire packet that looked at future expectations for the student (i.e., the likelihood of the student described dropping out of school), the need for academic support services (such as the student benefitting from extra tutoring in a certain subject), the personal characteristics of the described students (describing the student as competent vs incompetent based on the background information provided in the paragraph), believability (referring to the students in the paragraph and students in the actual school system behaving in similar manors), and SES (Auwarter \& Aruguete, 2008). The researchers found that teachers perceived that students from a higher SES do better academically and that varied expectations affect student performance (Auwarter \& Aruguete, 2008).

Auwarter and Aruguete's (2008) findings indicated that the perceptions teachers had about academic achievement in students from lower socioeconomic backgrounds did affect the teachers' willingness to work as hard for these students. This connects to social reproduction theory because the lower degree of willingness to actively work to reach low SES students aligns with the idea of schools perpetuating inequality and not providing equal opportunity for success to all students. Auwarter and Aruguete (2008) conducted a study in which teachers read paragraphs about hypothetical students who had academic and behavioral struggles. Based on the information provided in the student scenarios, the teacher participants perceived that students who were presented as being from a low SES had less potential for successful futures than did the hypothetical students portrayed as being from a higher SES (Auwarter\&Aruguete, 2008). The focus of this research on teacher perception of student SES and their readiness/ability to learn mathematics fit within the scope of social reproduction theory.

\subsection{Pertinent Literature}

Socioeconomic status. In general, students from disadvantaged backgrounds have been shown to achieve at a lower level that those from a higher SES (Cameron, Grimm, Steele, Castro-Schilo, \&Grissmer, 2015). In rural areas, families tend to fall into a lower SES, and these children have been shown to achieve less learning in high school mathematics than students from suburban or urban communities with a higher SES (Reeves, 2012). 
However, issues of poverty and populations of students from disadvantaged backgrounds are no longer only present in rural areas; school districts in suburban and urban communities are finding the need to address learning needs based on low SES, poverty, and homelessness as well (Wilson, 2012).

Many impoverished families do not have the resources or education to successfully engage and support their children's learning in the home environment (Lam, 2012). In an analysis of several research studies looking at the relationship between SES and student achievement, Lam (2012) concluded that SES is an important factor in determining student success, especially in elementary and middle school, and that educators need to seriously consider how the academic performance of students from low SES backgrounds can be improved. Low SES, which results in a lack of access to educational resources, affects student mathematics achievement as early as kindergarten (Galindo \&Sonnenschein, 2015). Lack of access to essential educational resources presents further barriers to student success in mathematics at all grade levels. Fewer opportunities for learning, less positive attention, and fewer instances of positive reinforcement are provided to students of low SES by both parents and teachers (Galindo \&Sonnenschein, 2015). Schools parents must partner in implementing strategies to provide positive support and encouragement to students both in and out of school in order to increase academic success (Bachman, Votruba-Drzal, El Nokah, \&Heatly, 2015). In elementary school, opportunities to learn, or lack thereof, contribute to the socioeconomic achievement gap (Bachman et al., 2015). The results of these studies together confirm that SES affects learning opportunities for students beginning at young ages, which in turn affects the level of achievement reached by low SES students.

Due to perceptions about the ability of students of a lower SES to learn, the opportunities to learn for these students are fewer, and these students are typically assigned to classrooms with less skilled, less qualified teachers (Bachman et al., 2015). High learning expectations should be held for all populations of students in order to encourage higher achievement. The gaps in mathematics and reading based on SES begin to emerge early in the school experience, and these gaps cause low-income students to struggle in other content areas as well (Galindo \&Sonnenschein, 2015). Teacher from all content areas should be equipped with strategies to implement in the classrooms so that these gaps diminish as the students' progress in school, not widen. Students from a lower SES are assigned to lower learning tracks, which results in fewer opportunities to engage with challenging content (McKown, 2013). SES alone should not be the determining factor when assigning students to learning tracks because student self-efficacy will not increase if they are not assigned challenging work at the appropriate level (McKown, 2013). Low socioeconomic students are frequently considered weaker students and subsequently are assigned the simplest, least complex tasks when working in groups (Bachman et al., 2015). The apparent perceptions possessed by educators are key factors in the ways students from low SES backgrounds are assigned to classes, which in turn contributes to widening learning gaps and less challenging work being given to the students in the classrooms (Bachman et al., 2015).

A large discrepancy in mathematics scores exists between advantaged and disadvantaged students, and underachievement is viewed as a direct result of poverty (Tienken, 2012). The issue of poverty and its effect on student learning has been associated with inner-city and rural communities; however, suburban schools are now experiencing an increase in low-income students who are struggling (Wilson, 2012). Understanding teacher perceptions of low SES students and their ability/readiness to learn is necessary to ensure equity in learning opportunities in the middle school mathematics classroom.

While SES many times is equated with low academic performance, there are those students from disadvantaged backgrounds who succeed academically. In their study, Huang and Zhu (2017) examined the role student determination and the disciplinary climate of the school and how they predicted low SES students being highly successful in mathematics and science. In this quantitative study, a sample of 4,978 15-year old students who had taken the Program for International Student Assessment U.S. in 2012 was used and their mathematics and science assessments were viewed. Demographic information such as individual student characteristics, family background and school characteristics were collected (Huang \& Zhu, 2017). Their findings showed that approximately 30\% of students whose families were categorized in the lowest quartile for SES had above average achievement in mathematics, and that school disciplinary climate and student grit had a significant relationship as to whether a low SES student was a high achiever (Huang \& Zhu, 2017). Parental involvement. Included in the SES of families and the effect on student success are parenting practices, background, and involvement. Mayo and Siraj (2015) looked at 35 different case studies in which children and parents were interviewed regarding parental involvement in school, the type of support provided at home to students, and the explanations from parents about their involvement/lack of involvement in their child's education. The findings of the study showed that when parents talked with their children about school daily, when parents were consistent in communicating the importance of school for the future, and when parents provided positive feedback and encouragement rather than pressuring their child the students were able to succeed beyond expectations (Mayo \& Siraj, 2015). 
Along the same lines, SES along with parental expectations play a role in student achievement. Using a sample of United States(U.S.) kindergarten students enrolled in the spring of 2000, Stull (2013) conducted a quantitative study looking at how SES and parental expectations affected student achievement. Student achievement data, parent interviews, teacher questionnaires, and administrator questionnaires were collected and analyzed using a regression analysis (Stull, 2013). The author concluded that family SES does affect the expectations parents have for their children, and SES both directly and indirectly affects the child's academic achievement (Stull, 2013).

Student motivation. According to the theory of social and cultural reproduction, a student's level of academic achievement is closely associated with the educational performance of his or her parents (Burger \& Walk, 2016). As inequality in education continues, many students become unmotivated to break this cycle. Burger and Walk (2016) recommended that future research be conducted that takes student ability and prior educational achievement into account and not simply the educational performance of the parents. The reason for this recommendation was that it will allow the "extent to which the effects of parental education on a child's outcomes mediated by family characteristics such as home learning environments or parenting strategies" affect student motivation and to gain insight into whether or not children may be able to break this cycle (Burger \& Walk, 2016, p. 708).

Engagement in mathematics declines during middle school, and factors associated with SES contribute to this decline (Martin, Way, Bobis, \& Anderson, 2015). In their study, Martin et al. (2015) looked at 1,601 sixth, seventh, and eighth grade students in 200 classrooms covering 44 different schools. Using the multilevel regression model to look at variables of school, class, and home factors, engagement in mathematics significantly decreased from sixth grade to eighth, with SES contributing to this finding (Martin et al., 2015). Teachers need to recognize the differences between low-income and higher-income students; the important factors affecting engagement (i.e., health and nutrition, vocabulary, effort, hope, cognition, relationships, and distress); the reasons for these differences; and what needs to be done to overcome the barriers to learning created by these differences (Jensen, 2013).

A student's SES can have a direct link to their educational and future aspirations. In their 2015 study of eighth grade students, Guo, Parker, Morin and Yeung (2015) found that students who came from higher SES backgrounds showed higher mathematics achievement as well as higher educational aspirations. The researchers also found that behaviors related to mathematics achievement could be positively predicted based on SES (Guo et al., 2015). Given these results, motivation to do well and to pursue educational aspirations can be directly affected by SES.

Students coming from low socioeconomic backgrounds face challenges unique to this population. Judging student motivation to succeed simply by looking at their SES can be a dangerous practice (McKay \& Devlin, 2016). McKay and Devlin (2016) recognized a need for low SES students to be empowered to succeed and to acknowledge that these students are "hard working, high achieving and determined to succeed" in most cases and that it is important for teachers to hold high expectations for all students regardless of socioeconomic background (p. 359).

Motivation in students can be affected by the support received from teachers inside of school. Yu and Singh (2018) looked at the relationship that teacher practices had on student motivation, especially in the area of high school mathematics. Their findings indicated that "when teachers care and respect students, and believe all students can be successful, students are more likely to believe they are capable in mathematics" (Yu \& Singh, 2018, p. 90). This includes low-income students. Yu and Singh cited that previous research shows "persistent achievement gaps among different ethnic groups and SES groups" (p. 91), indicating a need for future research using these specific population groups as participants.

Teacher preparation. Understanding the needs of diverse student populations is important for pre-service teachers. Preservice teacher placements, internships, student teaching and coursework are ways to help student teachers prepare for what they may encounter from diverse student populations in the classroom, including students from low socioeconomic backgrounds. In a 2016 study, Hanneke (2016) evaluated a course taken by student teachers in which the goal is to help them better understand how poverty impacts students. The goals of this course were to educate teachers on the obstacles faced by students from disadvantaged backgrounds, to ensure student teachers developed an understanding of factors behind the lower achievement levels of students from disadvantaged backgrounds and how teachers can increase or minimize this obstacle, and to ensure student teachers understood the facets of poverty and what power education actually has to impact it (Hanneke, 2016).

A study done by Graham, Robson, and Mtika (2019) examined how the social relationships of the five student teacher participants with their students and the connections they made helped lessen the effects of poverty on the students' academic outcomes. The study was done throughout the practicum experience of the student teachers, and through the interviews done with the participants, it was noted that the student teachers were not prepared in the context of the schools at which they were placed. According to Graham et al., "Practicum preparation must encompass the knowledge and skills for student teachers to enact pedagogy, including co-practice, beneficial for pupils living in poverty" (p. 133). 
The results of the study also revealed a crucial need for better preparation in supporting the professional learning of student teachers (Graham et al., 2019).

\section{Methodology}

The purpose of this qualitative, instrumental case study approach was to explore and gain insight into the perceptions and biases mathematics teachers may have, related to the ability of low SES students to learn mathematics. With the purpose of this study being to further understand how teacher perception regarding SES and the ability to learn affects instruction, this case was bound by the content area of mathematics and the physical boundary of middle school (i.e., Grades 6, 7, and 8). Though these bounds exists, teacher's experiences and perceptions which differed greatly. The research explored: (a) teachers' perceptions of how SES affects students' ability to learn, (b) what teachers believe affects their perceptions of low SES students, and (c) teachers' understanding of the use of culturally responsive teaching, in the cases of students from low socioeconomic backgrounds. The use of the case study approach was justified because the data generated came from the teachers' experiences and perceptions via semi-structured personal interviews. Examining the similarities and differences in the data aided in understanding the phenomenon more completely.

\subsection{Participants and Sampling}

The participants in this research study were mathematics teachers for Grades 6, 7 and 8 from a small, diverse, suburban school district. Due to the size of the district, the number of participants was targeted at 12 . However, less than 12 agreed to participate. The school district under study was a small, public district, with a population of 869 students in Grades 6-8, all housed in the district's only middle school building. Only nine of the mathematics teachers agreed to participate, and this was noted as a limitation of the research study. Purposeful convenience sampling was used to recruit the participants for this research study.

\subsection{Data Collection}

Data was collected through document analyses and interviews. Documents found on the school district website, such as the school improvement plan, were examined. Documents that were publicly available through the U.S. Department of Education provided contextual information. One annual document used as contextual information was the School District Report Cards from 2011-2016. This data showed an increase or decrease in standardized test scores in mathematics for middle school students for the past 5 years. This document also displayed the data for test scores broken down by SES. A second document used for contextual information was the School Committee Policy Manual, available on the district website. This document outlined the policy in place for meeting the needs of all students. Finally, a rubric for teacher evaluation; to identify the criteria used to determine if a teacher is effectively meeting the needs of all students, was also used.

Nine semi-structured individual interviews were conducted with the mathematics teacher participants. Interviews are a tool used by researchers to better understand the facts of and gain knowledge about the phenomenon being studied (Graham et al., 2019). According to Creswell (2012), semi-structured interviews are useful in small-scale educational research, such as this research study, due to the flexibility of the method. This research used a series of questions designed to acquire data about teacher biases, experiences with low socioeconomic individuals, factors that teachers believe influence their perceptions, and what the perceptions were of students from low socioeconomic backgrounds related to ability to learn. The interview questions were developed based on the data desired for the research study, as well as the use of the definition of social reproduction theory. Table 1 shows the research questions.

\section{Data Analysis}

Interviews. Interview data were coded and analyzed using NVivo software and themes began to emerge. Each participant was notified of the emergent themes and was also informed as to which participant number pertained to him/her so that he/she could pay closer attention to his/her own contributions to the data. The provided feedback was documented for accuracy. Interviews were transcribed verbatim and each transcription completed immediately following the interview using NVivo software. Following the transcription process, results were coded using color codes to identify text segments.

Data collection from the personal interviews and document studies were fully analyzed once all interviews were completed, and data was coded using NVivo coding to identify commonalities emerging from the analysis. Codes were listed and examined for redundancy, and categories were developed. Codes were categorized, and themes were identified from the categorized codes. The themes identified from the data analysis were in alignment with the framework of social reproduction theory as described by Creswell (2012). The themes also aligned with the arguments of Auwarter and Aruguete (2008) in their study examining student success based on socioeconomic status and gender. 
Documents. Data for this research study were generated through direct analysis of publicly available documents from a small suburban school district. The mathematics test scores for Grades 6, 7, and 8 over a 5-year period (2011-2016) were analyzed for gaps between disadvantaged and no disadvantaged students. The analysis showed a slowly widening gap in these scores. The interviews were audio recorded and immediately transcribed verbatim using NVivo software. Following the interviews, all data was analyzed using NVivo software in order to identify themes, patterns and relationships.

\section{Findings}

The findings of this research study were organized by the categories emerging from the data analysis, which are: academic performance, behavior, communication, expected student characteristics, personal experiences and influences on perceptions of low SES students, preparation to teach the population of low SES students (including professional development), and student support in and out of school. Table 2 shows the alignment of themes to the research questions addressed in this study.

\section{Findings for Research Question 1}

The participants interviewed shared that they do see these students performing at a lower level academically and the students may not have the same opportunities for success as their peers coming from higher socioeconomic backgrounds. The teacher participants felt that SES did affect their students' ability to learn mathematics. There were three areas the teacher participants saw as problematic for the lower SES students. They were, foundational skills, mindset and willingness to learn, and ability to learn related to SES. Many participants stated that they see very weak foundational mathematics skills in their students coming from low socioeconomic backgrounds. The teacher participant interviews categorized low SES student behavior in the classroom and the ability to succeed in mathematics into three groups: motivated students and mathematics success; unmotivated students and mathematics success; and no correlation between behavior and mathematics success. The teacher participants reported that they usually see low SES students as unprepared, unengaged, and making excuses for why work is not complete or why they are not achieving in class. Teacher participants also stated that the students from low socioeconomic backgrounds also show poor behavior due to frustration and stress and can become very disruptive to the learning of the rest of the class. The data stemming from teacher participant interviews regarding communication shows that the teachers believe communication between them and parents, them and students, and among each other is extremely important in helping students from low socioeconomic backgrounds succeed. The teacher participants all agreed that opening a line of communication with parents is important, and that the line needs to stay open. Teacher participants generally seemed to want to support students and parents, but they also believe that the parents and students must be willing to reciprocate and do their part for the student to succeed. E-mail communication seemed to be the preferred method of reaching out to parents, and several opportunities for parents to come in to meet with teachers are provided throughout the year. The characteristics of students from SES backgrounds expected by the teachers interviewed were extremely similar across the board. The expected characteristics discussed most were lack of a desire to learn; difficulty with comprehension due to lack of focus; disrespectful attitudes; lack of participation in class; and attitude of defeat. This data aligns with research question 1 in that due to the characteristics of disadvantaged students expected by the teacher participants, the teacher participants felt there was nothing they would be able to do to reach these students from the get-go. This data also aligns with Research Question 1 because the teacher participants perceived the characteristics expected in the students hinder the achievement in mathematics.

Teacher participants identified support at home as a significant indicator of how well a student from a lower socioeconomic background will succeed. They shared that many times nobody is home to help with homework, there is not an appropriate place for homework to be completed, the students are caring for younger siblings, and having enough food is an issue. Often, these students are exhausted. In addition, the teacher participants found that when they tried to contact parents regarding student performance, either there was no response or the response was, "I don't understand mathematics, so I can't help."

There were two discrepant cases in the findings for Research Question 1. Two of the teacher participants strongly felt that SES did not have any effect on students' ability to learn mathematics. These two teacher participants believed that students from low socioeconomic backgrounds succeed if they have a mindset for success. The teacher participants also believed that motivation, determination and effort contributed more to student success than SES. These two cases were noted as discrepant in the study findings.

\section{Findings for Research Question 2}

Each teacher participant interviewed had personal experiences, whether as children themselves or as adults, with individuals coming from a low socioeconomic background. 
They agreed that their personal experiences did have a significant influence on their perceptions of students coming from a disadvantaged background. Several of the teachers shared that they came from difficult backgrounds themselves, and that their attitudes towards learning were strong because of their experiences as students. These teacher participants stated they now expect students from low socioeconomic circumstances to have a future if they are willing to participate in their education and push to succeed.

The data gathered from the teacher participant interviews; regarding the preparation they have received to meet the academic needs of low socioeconomic students, both via teacher preparation programs and professional development, align with Research Question 2 because the interviews revealed that the teacher participants' preparation, or lack of preparation, to teach this population of students influenced their perceptions of the students' abilities to learn mathematics. The teacher participants unanimously stated that there needs to be more information given and professional development provided on how to help students from disadvantaged backgrounds succeed in mathematics, and in school in general, to their full potential.

\section{Summary of the Data}

In general, the teacher participants felt that coming from a low socioeconomic background did negatively impact a student's ability to learn mathematics. They identified attitude, willingness to learn, and support both in and out of school as significant factors contributing to student success and agreed that students coming from disadvantaged backgrounds tend to have a much lower level of support at home, impacting their learning. Two discrepant cases were noted where the participants did not agree there was a connection between low SES and the ability to learn mathematics.

The teacher participants interviewed felt that their own personal experiences with individuals from low socioeconomic backgrounds played a role in the formation of their perceptions of this student population. In addition, they felt that discussions with teachers who had taught the students previously contributed to the continuation of these perceptions, even before they had the opportunity to teach the students themselves. Observed behavior by the students in the class also factored into the teachers' perceptions of students from low socioeconomic backgrounds.

Finally, the teacher participants interviewed unanimously communicated that more needs to be done both in teacher preparation programs and in professional development opportunities to better equip teachers to meet the needs of students from low socioeconomic backgrounds. While they have been exposed to teaching and professional development for serving students with special needs and for English language learners, they have not experienced professional instruction in the unique needs of disadvantaged students and how to help them succeed in learning the intricacies of mathematics. All the teachers participating expressed an excitement in the possibility that this type of professional learning could possibly be an option in the future.

\section{Conclusions}

The purpose of the research was to understand mathematics teachers' perceptions of the ability of students coming from low socioeconomic backgrounds to learn mathematics and to better understand what factors the teachers believed helped form these perceptions. The method chosen to pursue these questions was a qualitative case study of a local middle school based on publicly available data showing a gap in mathematics scores between students categorized as "economically disadvantaged" versus "economically no disadvantaged." The research findings revealed gaps in teacher knowledge of the needs of disadvantaged students, communication between teachers and other departments regarding this student population, opportunities for increased student support both in and out of school, and opportunities for more focused professional development. Potential implications of providing increased knowledge to teachers and support to families and students are increased parent involvement and increased student achievement. This research was grounded in social reproduction theory. Specific themes were identified through the process of coding, and data were organized accordingly. The findings revealed several areas affected by teacher perceptions as well as factors identified by teachers as contributing to the formation of their perceptions. The resulting research was a position paper explaining the study findings and making recommendations to school leadership in each of the areas regarding students from low socioeconomic backgrounds, their families, and teacher-identified gaps. The positive social change anticipated by the implementation of the recommendations is the increased understanding and ability of teachers to meet the needs of underprivileged students, increased support and involvement for families of these students, and increased student achievement in the local middle school as a result. The findings of this study provide direction for possible future research. Studies could be undertaken to look at the actual outcomes for students in districts where specific professional development has been provided to teachers to meet the needs of impoverished students. Research on the outcomes of students from low socioeconomic backgrounds whose teachers were provided coursework and practicum experiences during their preparation programs targeted to this student population could also be conducted. 
Finally, research on perceptions of teachers in content areas other than mathematics and at educational levels other than middle school about disadvantaged students and how those perceptions affect instruction could be performed.

Table 1.

Alignment of Interview Questions to Research Questions and Social Reproduction Theory Elements

Presented by Auwarter and Aruguete (2008)

Interview Questions

1. How do you perceive how students' socioeconomic status affects their ability to learn mathematics?

2. What characteristics have you encountered in students from lower socioeconomic backgrounds that lead you toward this perception?

3. How have these characteristics classroom? 2008)

4. Did you anticipate encountering these characteristics in this student population? Why or why not?
Research Question or

Element
RQ1 (Qualitative): How do grades

6, 7 and 8 mathematics teachers perceive how their students' socioeconomic status affects their ability to learn mathematics?

"Personal characteristics of the student" (Auwarter\&Aruguete, 2008)

"Personal characteristics of manifested in the the student" (Auwarter et al.,

RQ2 (Qualitative): What do grades

6, 7 and 8 mathematics teachers

believe influences their own perceptions of students' ability to learn mathematics?

5. How did you know to anticipate differences RQ2 (Qualitative): What do grades in this student population regarding learning mathematics?

6, 7 and 8 mathematics teachers believe influences their own perceptions of students' ability to learn mathematics?

Socioeconomic status" (Auwarter et al., 2008)

"Socioeconomic status" (Auwarteret

al., 2008)

"Believability" (Auwarter et al., 2008)

"Need for academic services"

(Auwarter et al., 2008)

"Socioeconomic status" (Auwarter et al., 2008)

"Characteristics of the student"

(Auwarter et al., 2008) 
8. What strategies are used to mitigate the difference in mathematics performance?

9. What do you believe influences your own perceptions of students' ability to learn mathematics?

10. What personal experiences with economically disadvantaged students have you had that contributed to the formation of your perceptions?

11. What barriers have these perceptions created?

12. What preparation for teaching mathematics to student from low socioeconomic backgrounds specifically have you been provided through your teacher preparation program?
RQ1 (Qualitative): How do grades

6, 7 and 8 mathematics teachers perceive how their students' socioeconomic status affects their ability to learn mathematics?

"Need for academic services" (Auwarter et al., 2008)

RQ2 (Qualitative): What do grades 6,7 and 8 mathematics teachers believe influences their own perceptions of students' ability to learn mathematics?

RQ2 (Qualitative): What do grades 6, 7 and 8 mathematics teachers believe influences their own perceptions of students' ability to learn mathematics?

"Future expectations" (Auwarter et al., 2008)

RQ2 (Qualitative): What do grades 6, 7 and 8 mathematics teachers believe influences their own perceptions of students' ability to learn mathematics?

13. What types of professional development "Socioeconomic status" have you been offered in teaching (Auwarter et al., 2008) mathematics effectively to economically disadvantaged students?

14. How have you implemented what you learned through the professional development in the classroom?

"Future expectations"

(Auwarter et al., 2008)

"Believability"

(Auwarter et al., 2008)

"Need for academic services"

(Auwarter et al., 2008)

Table 2

Alignment of Themes and Subthemes to Research Questions

\begin{tabular}{lll}
\hline Themes & \multicolumn{1}{c}{ Subthemes } & \multicolumn{1}{c}{ Research Question } \\
\hline Academic performance & Low foundational skills & RQ1 (Qualitative): \\
& Mindset/willingness to learn & What are grades 6,7,
\end{tabular}




\begin{tabular}{|c|c|c|}
\hline & Ability to learn & $\begin{array}{l}\text { and } 8 \text { mathematics } \\
\text { teachers' perceptions } \\
\text { about how their } \\
\text { students' socio- } \\
\text { economic status } \\
\text { affects the ability } \\
\text { to learn mathematics? }\end{array}$ \\
\hline Classroom behavior & $\begin{array}{l}\text { Motivated, rested } \\
\text { students are more } \\
\text { resilient and have more } \\
\text { positive behavior, therefore } \\
\text { achieving higher }\end{array}$ & $\begin{array}{l}\text { RQ1 (Qualitative): } \\
\text { What are grades } 6,7, \\
\text { and } 8 \text { mathematics } \\
\text { teachers' perceptions } \\
\text { about how their } \\
\text { students' socio- } \\
\text { economic status } \\
\text { affects the ability } \\
\text { to learn mathematics? }\end{array}$ \\
\hline Communication & $\begin{array}{l}\text { Students whose parents } \\
\text { communicate with } \\
\text { teachers achieve } \\
\text { at higher levels }\end{array}$ & $\begin{array}{l}\text { RQ1 (Qualitative): } \\
\text { What are grades 6, } 7 \text {, } \\
\text { and } 8 \text { mathematics } \\
\text { teachers' perceptions } \\
\text { about how their } \\
\text { students' socio- } \\
\text { economic status } \\
\text { affects the ability to } \\
\text { learn mathematics? }\end{array}$ \\
\hline $\begin{array}{l}\text { Expected characteristics } \\
\text { of low SES students }\end{array}$ & $\begin{array}{l}\text { Low SES students } \\
\text { show a lack of desire to learn, } \\
\text { focus, respect and participation. } \\
\text { Have an attitude of defeat. }\end{array}$ & $\begin{array}{l}\text { RQ1 (Qualitative): } \\
\text { What are grades 6, } 7 \text {, } \\
\text { and } 8 \text { mathematics } \\
\text { teachers' perceptions } \\
\text { about how their } \\
\text { students' socio- } \\
\text { economic status } \\
\text { affects the ability to } \\
\text { learn mathematics? }\end{array}$ \\
\hline Influences on perceptions & $\begin{array}{l}\text { Personal experiences } \\
\text { Personal background } \\
\text { Conversations with other teachers }\end{array}$ & $\begin{array}{l}\text { RQ2 (Qualitative): } \\
\text { What do grades 6, } 7 \text {, } \\
\text { and } 8 \text { mathematics } \\
\text { teachers believe } \\
\text { influences their own } \\
\text { perceptions of } \\
\text { students' ability to } \\
\text { learn mathematics? }\end{array}$ \\
\hline $\begin{array}{l}\text { Preparation to teach low SES } \\
\text { students }\end{array}$ & $\begin{array}{l}\text { No preparation in college } \\
\text { No professional development }\end{array}$ & $\begin{array}{l}\text { RQ2 (Qualitative): } \\
\text { What do grades 6, } 7 \text {, }\end{array}$ \\
\hline
\end{tabular}


and 8 mathematics

teachers believe influences their own

perceptions of

students' ability to

learn mathematics?

Student support

\section{References}

No support outside of school

Not enough support offered

inside of school

More needs to be done to

encourage parent involvement
RQ1 (Qualitative):

What are grades 6, 7, mathematics teachers'

perceptions about how their students' socioeconomic status affects the ability to learn mathematics?

Auwarter, A. E., \&Aruguete, M. S. (2008). Effect of student gender and socioeconomic status on teacher perceptions. The Journal of Educational Research, 243-246.https://doi.org/10.3200/JOER.101.4.243-246

Bachman, H. J., Votruba-Drzal, E., El Nokali, N. E., \&Heatly, M. C. (2015). Opportunities for learning math in elementary school: Implications for SES disparities in procedural and conceptual math skills. American Educational Research Journal, 52(5), 894-923.https://doi.org/10.3102/0002831215594877

Basque, M., \&Bouchamma, Y. (2016). Predictors of mathematics performance: The impact of prior achievement, socioeconomic status and school practices. International Studies in Educational Administration, 44(1), 85104.Retrieved from https://search-ebscohostcom.ezp.waldenulibrary.org/login.aspx?direct=true $\& d b=e u e \& A N=118569373 \&$ site $=$ eds-live $\&$ scope $=$ site.

Burger, K., \& Walk, M. (2016). Can children break the cycle of disadvantage?

Structure and agency in the transmission of education across generations. Social Psychology of Education, 19, 695713.https://doi-org.ezp.waldenulibrary.org/10.1007/s11218-016-9361-y

Byerley, L., Lane, H., Ludy, M., Vitolins, M. Z., Anderson, E., Niedert, K., ... Abram, J. (2017). Ethical considerations for successfully navigating the research process. Journal of the Academy of Nutrition and Dietetics, 117(8), 1302-1307.https://doi.org/10.1016/j.jand.2017.02.011

Cameron, C. E., Grimm, K. J., Steele, J. S., Castro-Schilo, L., \&Grissmer, D. W. (2015). Nonlinear Gompertz curve models of achievement gaps in mathematics and reading. Journal of Educational Psychology, 107(3), 789804.https://doi.org/10.1037/edu0000009

Collins, J. (2009). Social reproduction classrooms and schools. Annual Review of Anthropology, 38, 3348.https://doi.org/10.1146/annurev.anthro.37.081407.085242

Creswell, J. W. (2012). Educational research: Planning, conducting, and evaluating quantitative and qualitative research. Boston, MA: Pearson Education, Inc.

Galindo, C., \&Sonnenschein, S. (2015). Decreasing the SES math achievement gap: Initial math proficiency and home learning environments. Contemporary Educational Psychology, 43, 25-38. https://doi.org/10.1016/j.cedpsych.2015.08.003

Graham, A., MacDougall, L., Robson, D., \&Mtika, P. (2019). Exploring practicum: Student teachers' social capital relations in schools with high numbers of pupils living in poverty. Oxford Review of Education, 45(1), 119135.https://doi.org/10.1080/03054985.2018.1502079

Guo, J., Marsh, H. W., Parker, P. D., Morin, A. J. S., \& Yeung, A. S. (2015). Expectancy-value in mathematics, gender and socioeconomic background as predictors of achievement and aspirations: A multi-cohort study. Learning and Individual Differences, 37, 161-168.https://doi.org/10.1016/j.lindif.2015.01.008

Hanneke, J. (2016). Discussing poverty with student teachers: The realities of dialogue. Journal of Education for Teaching,42(4), 468-482. https://doi.org/10.1080/02607476.2016.1215553

Huang, H., \& Zhu, H. (2017). High achievers from low socioeconomic backgrounds: The critical role of disciplinary climate and grit. Mid-Western Educational Researcher, 29(2), 93-116.Retrieved from https://search-ebscohostcom.ezp.waldenulibrary.org/login.aspx?direct=true \&db=eric\&AN=EJ1150729\&site=eds-live \&scope=site 
Jensen, E. (2013). How poverty affects classroom engagement. Educational Leadership, 70(8), 24-30.Retrieved from https://search-ebscohost-

com.ezp.waldenulibrary.org/login.aspx $?$ direct=true $\& d b=$ eric $\& A N=E J 1029042 \&$ site $=$ eds-live $\&$ scope $=$ site

Lam, G. (2012). A theoretical framework of the relation between socioeconomic status and academic achievement of students. Education, 134(3), 326-331.Retrieved from

https://search-ebscohost-

com.ezp.waldenulibrary.org/login.aspx $?$ direct=true $\& \mathrm{db}=$ eric $\& A N=E J 1034279 \&$ site $=$ eds-live \&scope $=$ site

Martin, A. J., Way, J., Bobis, J., \& Anderson, J. (2015). Exploring the ups and downs of mathematics engagement in the middle years of school. Journal of Early Adolescence, 35(2), 199-244. https://doi.org/10.1177/0272431614529365

Mayo, A., \& Siraj, I. (2015). Parenting practices and children's academic success in low-SES families. Oxford Review of Education, 41(1), 47-63.https://doi.org/10.1080/03054985.2014.995160

McKay, J., \& Devlin, M. (2016) 'Low income doesn't mean stupid and destined for failure': Challenging the deficit discourse around students from low SES backgrounds in higher education. International Journal of Inclusive Education, 20(4), 347-363.https://doi.org/10.1080/13603116.2015.1079273

McKown, C. (2013). Social equity theory and racial-ethnic achievement gaps. Child Development, 84(4), 11201136.https://doi.org/10.1111/cdev.12033

Powers-Costello, B., \& Swick, K. J. (2011). Transforming teacher constructs of children and families who are homeless. Early Childhood Education, 39, 207-212.https://doi.org/10.1007/s10643-011-0455-z

Reeves, E. B. (2012). The effect of opportunity to learn, family socioeconomic status, and friends on the rural math achievement gap in high school. American Behavioral Scientist, 56(7), 887-907. https://doi.org/10.1177/0002764212442357

Rollin, S. (2013). Teachers, students, and the impact of social class. Middle School Journal, 44(4), 50-55. https://doi.org/10.1080/00940771.2013.11461864

Sieben, N. \& Johnson, L. L. (2018). Professional development pathways through social justice frameworks. English Education, 50(2), 108-115.

Stull, J. C. (2013). Family socioeconomic status, parent expectations, and a child's achievement. Research in Education, 90, 53-67.https://doi.org/10.7227/RIE.90.1.4

Tienken, C. H. (2012). The influence of poverty on achievement. Kappa Delta Pi Record, 105107.https://doi.org/10.1080/00228958.2012.707499

Tomul, E., Celik, K., \& Tas, A. (2012). Justice in the classroom: Evaluation of teacher behaviors according to students' perceptions. Eurasian Journal of Educational Research, 48, 59-72.

Wilson, D. M. (2012). Struggling in suburbia. Teaching Tolerance, 42, 40-43.Retrieved from https://search-ebscohostcom.ezp.waldenulibrary.org/login.aspx?direct=true $\& d b=$ edswss $\& A N=000312228200004 \&$ site $=$ edslive \&scope $=$ site

Yu, R., \& Singh, K. (2018). Teacher support, instructional practices, student motivation, and mathematics achievement in high school. The Journal of Educational Research, 111(1), 81-94. https://doi.org/10.1080/00220671.2016.1204260 